\title{
Audit of Day Case Thyroidectomy - Is it Safe?
}

\author{
Miss J Narayan, Mr R Hughes \\ University Hospital of N Midlands, Stoke-on-Trent, UK
}

\section{Background:}

With innovation in anaesthetic techniques, surgical tools and improved preoperative preparation, ENT day surgery rates have increased ${ }^{1}$ despite lack of specific identified variables for safe day surgery thyroidectomy ${ }^{2}$ and BAETS position on day surgery ${ }^{3}$.

\section{Objectives:}

To review results from 2 audit cycles and compare with the 5th national audit $2017^{4}$. Results were used to inform department guidelines.

\section{Methods:}

- Retrospective audit of consecutive patients undergoing thyroid lobectomy or hemithyroidectomy (35 patients) in 2017 and (30 patients) in 2015 were included

- Data collected from electronic hospital systems: patient factors; length of stay; surgical factors and significant complications

- Standards - based on complications significant to day surgery: Haematoma (reported rates: $0.9 \%-2.1 \%$ \& could be life threatening); 30 day mortality; Readmission rate

- Presented and discussed at department audit meeting

\section{Results 1: Patient Demographics: Gender} 2015 Sex ratio 1: 6.5
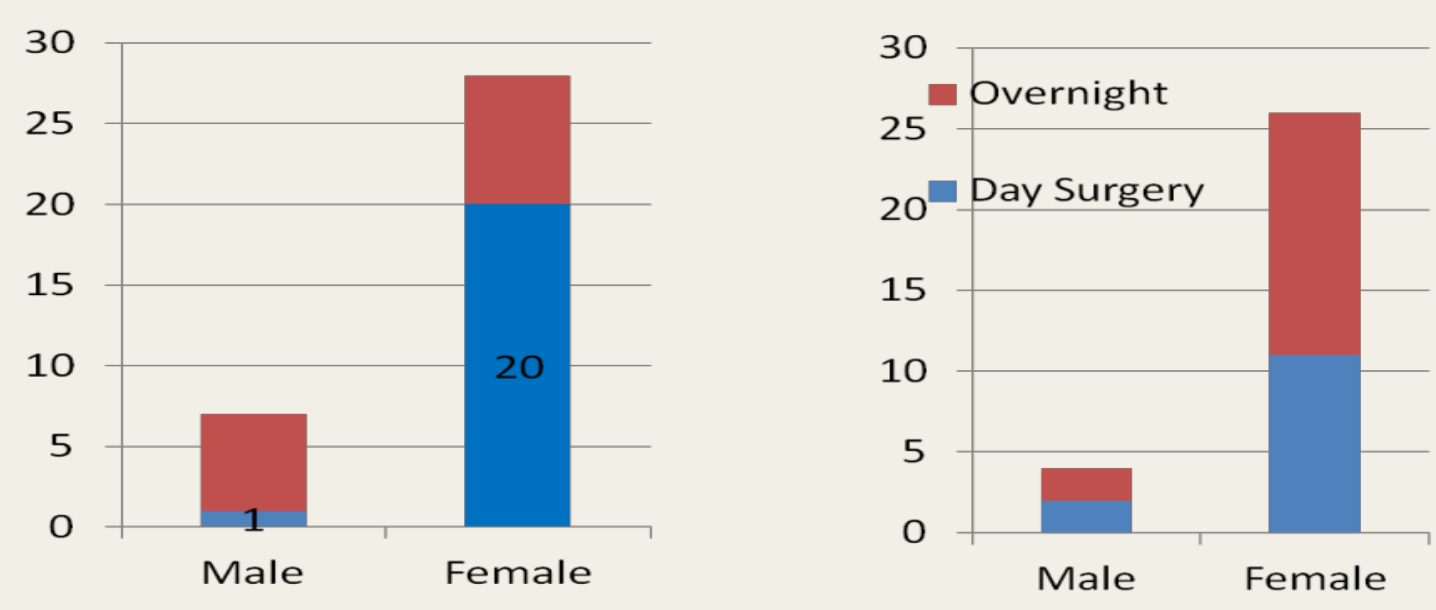

BAETS: no significant change in demographic profile...strong female predominance.. 4:1

Results 1: Patient Demographics: Age
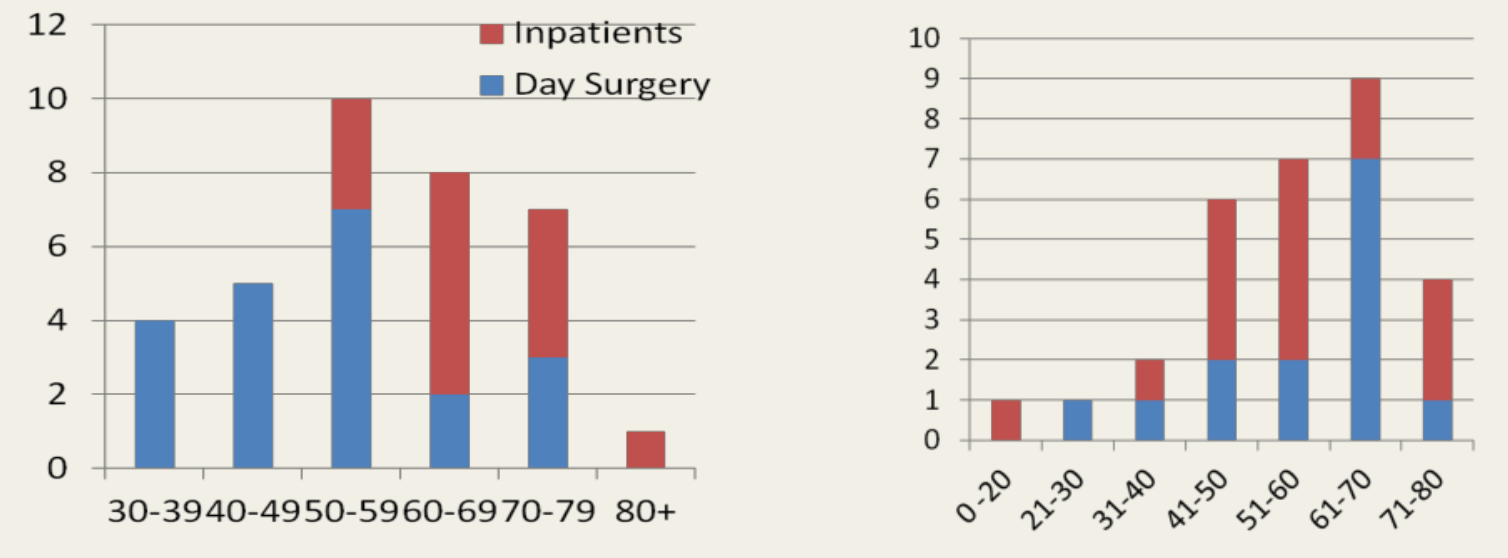

2017 Mean age 57y; Median age 58y

2015 Mean age 55.4y; Median age 57y

Results 2: Patient Factors: ASA grading
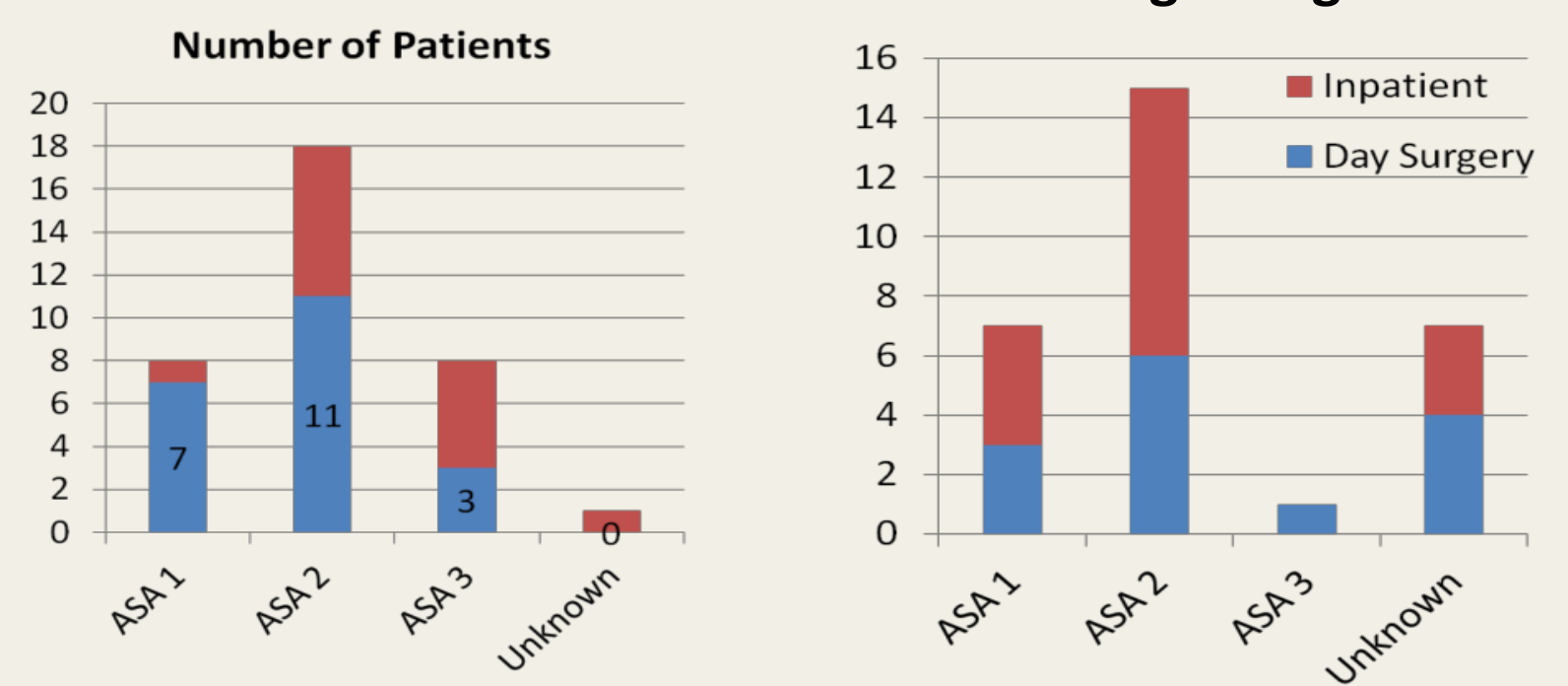

Day Case

Suggested Guidelines for Thyroidectomy

GA lasting $<100 \mathrm{~min}$

ASA Grade 1, some Grade 2

Young patients $<60 \mathrm{y}$

Not on anticoagulants

Hemithyroidectomy/ Lobectomy
Inpatient

Retrosternal Goitre

Hyperthyroidism

On anticoagulants

Drain insertion

ASA Grade 3

Completion / Total Thyroidectomy

Prolonged surgery
Results 2: Patient Factors: Histology
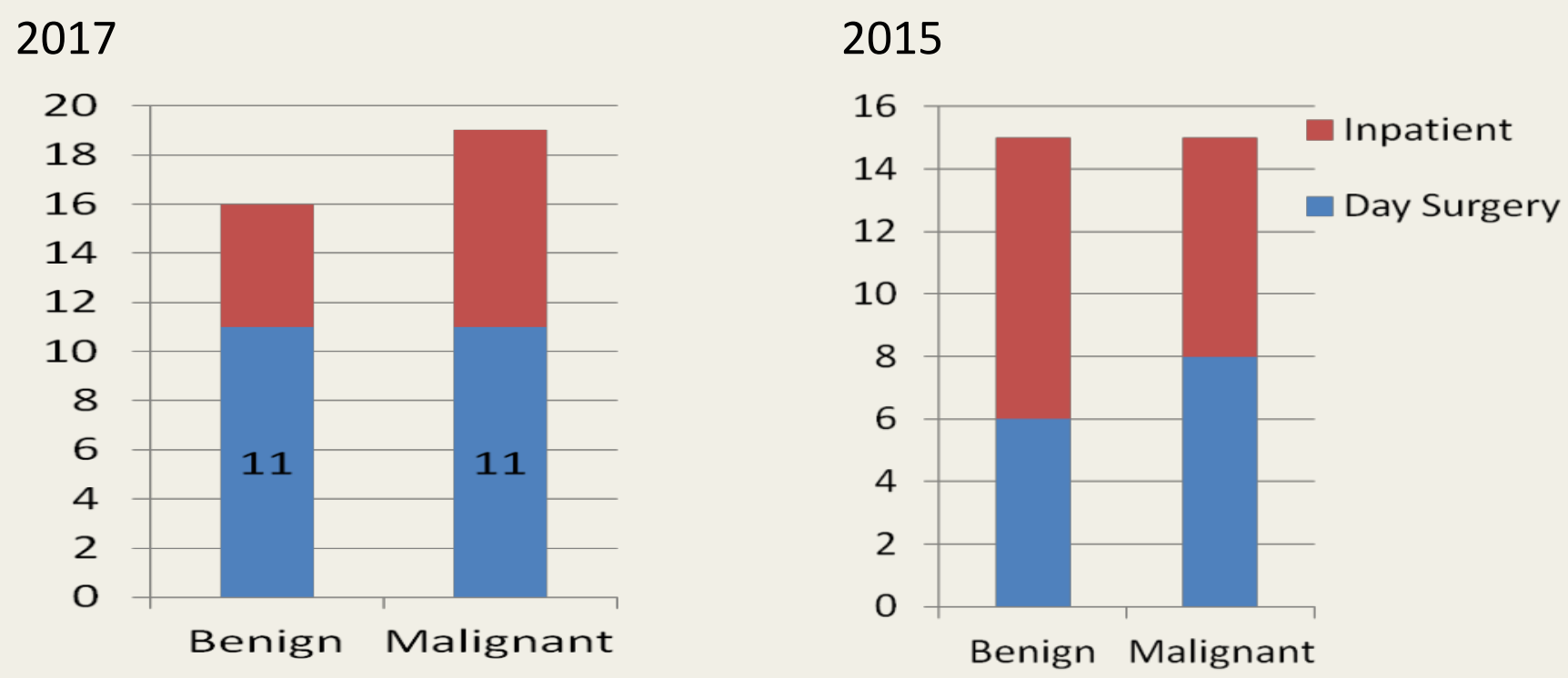

Our series 50\% (2015) -54\% (2017) malignant

BAETS: Between 19\%-36.7\% had primary cancer diagnosis (all types)

\section{Results 3: Length of Stay: Number of Postoperative days in hospital}
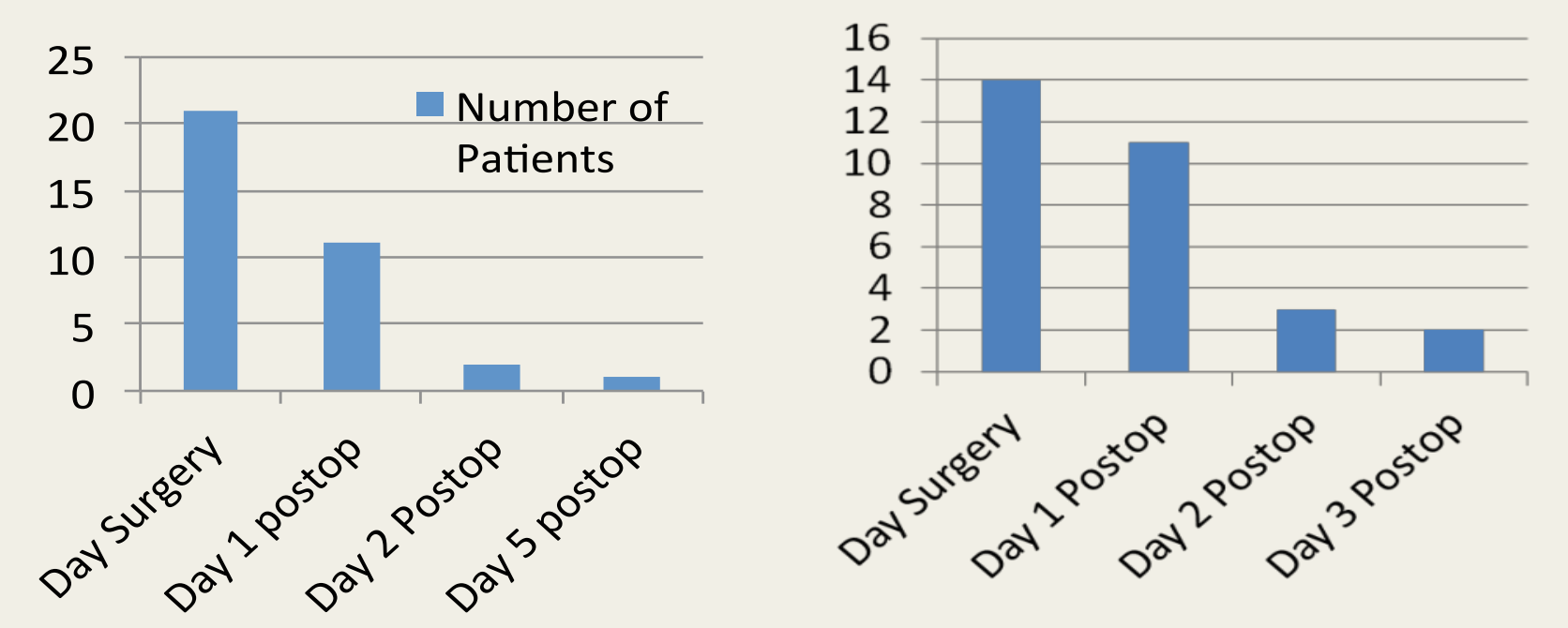

$60 \%$ of patients went home on the day of surgery in 2017 and $46 \%$ in 2015

Results 4: Surgical Factors: First Surgeon/Consultant
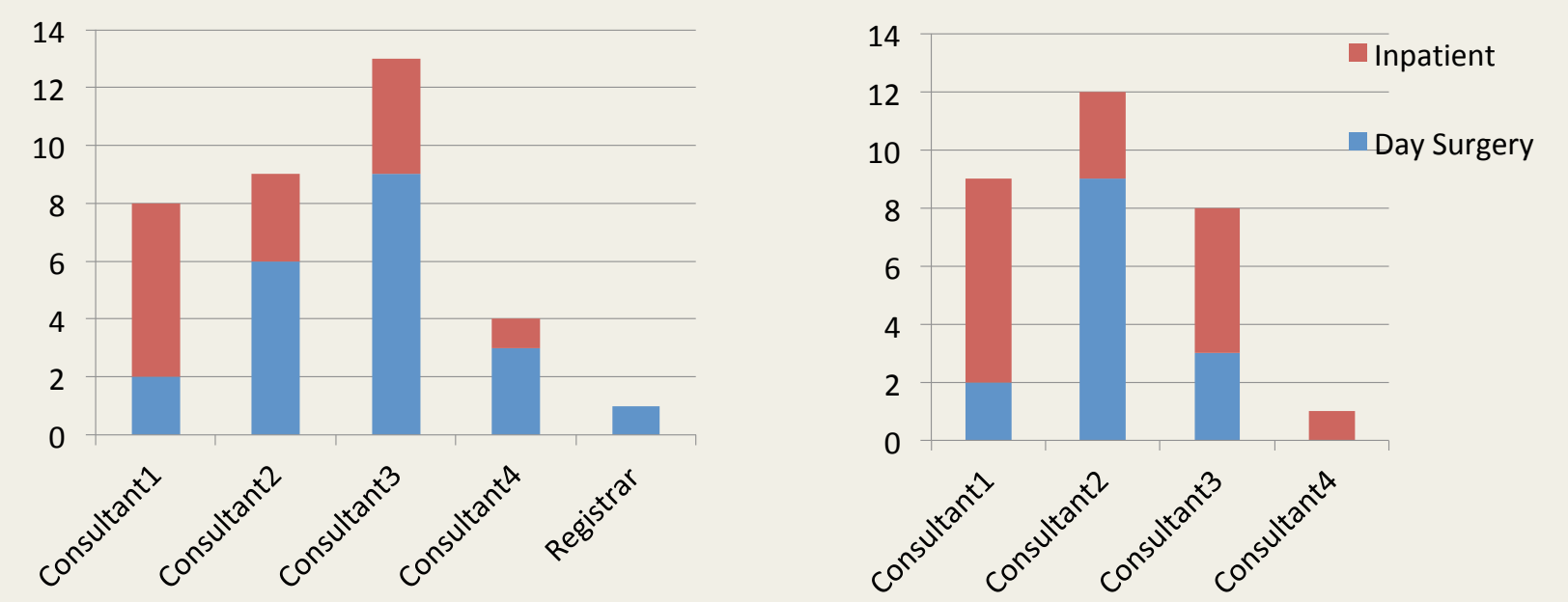

Results 4: Surgical Factors: Time under General Anaesthesia (Surgical + Anaesthetic time) in Minutes

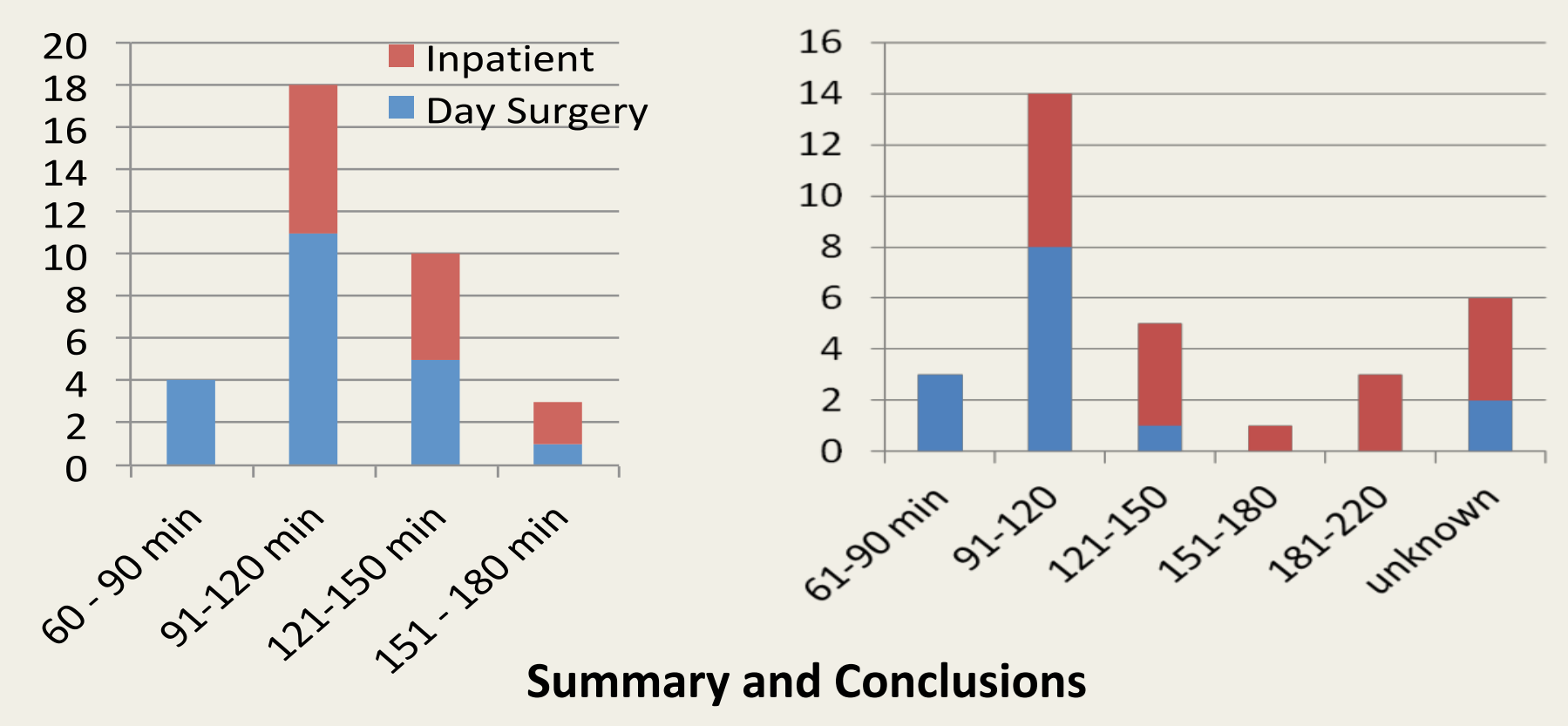

- Consecutive audits indicate Day Surgery (partial) Thyroidectomy can be carried out safely (by high volume surgeons) in carefully selected patients, who are Fit, Young and have General Anaesthesia lasting $\leq 100$ minutes.

- While none of the day surgery patients required readmission or suffered significant complications, there were readmissions for sepsis, haematoma and seroma among the inpatients.

\section{References}

1 Day case thyroid surgery is acheivable! HS Khaira www.bads.co.uk

2 Mullen et al. Risk factors for 30-day hospital readmission after thyroidectomy and parathyroidectomy in the United States: An analysis of National Surgical Quality Improvement Program outcomes. Surgery; Dec 2014; vol. 156 (no. 6); p. 1423

3 Questionable safety of thyroid surgery with same day discharge. HE Doran, J England, F Palazzo Ann R Coll Surg Engl 2012; 94: 543-547

4 Fifth National Audit Report 2017; The British Association of Endocrine and Thyroid Surgeons 